\title{
Development and applications of VSV vectors based on cell tropism
}

\author{
Hideki Tani $^{1}{ }^{*}$, Shigeru Morikawa ${ }^{1}$ and Yoshiharu Matsuura ${ }^{2}$ \\ 1 Special Pathogens Laboratory, Department of Virology I, National Institute of Infectious Diseases, Musashimurayama, Tokyo, Japan \\ ${ }^{2}$ Department of Molecular Virology, Research Institute for Microbial Diseases, Osaka University, Suita, Osaka, Japan
}

\section{Edited by:}

Akio Adachi, The University of

Tokushima Graduate School, Japan

Reviewed by:

Ikuo Shoji, Kobe University Graduate

School of Medicine, Japan

Tatsuo Shioda, Osaka University,

Japan

*Correspondence:

Hideki Tani, Special Pathogens

Laboratory, Department of Virology I,

National Institute of Infectious

Diseases, 4-7-1 Gakuen,

Musashimurayama, 208-0011 Tokyo,

Japan.

e-mail: htani@nih.go.jp
Viral vectors have been available in various fields such as medical and biological research or gene therapy applications. Targeting vectors pseudotyped with distinct viral envelope proteins that influence cell tropism and transfection efficiency are useful tools not only for examining entry mechanisms or cell tropisms but also for vaccine vector development. Vesicular stomatitis virus (VSV) is an excellent candidate for development as a pseudotype vector. A recombinant VSV lacking its own envelope (G) gene has been used to produce a pseudotype or recombinant VSV possessing the envelope proteins of heterologous viruses. These viruses possess a reporter gene instead of a VSV G gene in their genome, and therefore it is easy to evaluate their infectivity in the study of viral entry, including identification of viral receptors. Furthermore, advantage can be taken of a property of the pseudotype VSV, which is competence for single-round infection, in handling many different viruses that are either difficult to amplify in cultured cells or animals or that require specialized containment facilities. Here we describe procedures for producing pseudotype or recombinant VSVs and a few of the more prominent examples from envelope viruses, such as hepatitis $\mathrm{C}$ virus, Japanese encephalitis virus, baculovirus, and hemorrhagic fever viruses.

Keywords: vesicular stomatitis virus, pseudotype, recombinant, entry mechanism

\section{INTRODUCTION}

Viruses are obligate parasites of living organisms, and their replication is absolutely dependent on the host cell's machinery. The entry of enveloped viruses requires host cell binding and membrane fusion that is mediated by envelope proteins located on the surface of the virion.

Some viruses utilize a single molecule as a receptor for entry into the host cell, while many viruses require co-receptor(s) localized near the receptor for complete entry. Identification of viral entry receptors that are composed of membrane proteins, lipids, or carbohydrates is important for examining the life cycle of a virus and for further developing entry inhibitors. However, receptors or co-receptors of several viruses have been difficult to identify because of the lack of reliable cell culture systems, an insufficient amount of native viral particles, or difficulty in handling because of the requirement for biosafety level (BSL)-3 or -4 containment. Therefore, several surrogate systems have been developed to study the initial step of infection. One of the most primitive assays is a binding assay. Purified soluble envelope proteins, viral-like particles which are produced in insect cells by baculoviral vectors, and authentic viral particles obtained from patients have been used to study the mechanisms of viral attachment and to identify binding receptor molecules. However, these binding assays cannot be used to analyze further steps of infection such as fusion and penetration. A cell fusion assay was established to examine the membrane fusion activity of viral envelope proteins. This assay is sensitive and can easily determine cell fusion using reporter genes. Pseudotype virus systems based on vesicular stomatitis virus (VSV), influenza virus, retroviruses, and lentiviruses have also been established to examine entry mechanisms and to identify putative entry receptors for targeted viruses (Table 1). Pseudotype viruses have also been applied in neutralization tests for antibodies and vaccine development (Table 1). As for the application of a pseudotype virus system for VSV, a recombinant virus system with a heterologous viral envelope gene together with a reporter gene encoded into its own genome instead of the $\mathrm{G}$ gene has also been developed.

In this paper, we describe the properties of pseudotype or recombinant VSVs and their application to some enveloped viruses we have studied, such as the hepatitis C virus (HCV), Japanese encephalitis virus (JEV), baculovirus, and hemorrhagic fever viruses.

\section{PSEUDOTYPE AND RECOMBINANT VSV}

Vesicular stomatitis virus is a non-segmented, negative-stranded RNA virus that belongs to the family Rhabdoviridae, genus Vesiculovirus. VSV infects a broad range of animals, including cattle, horses, and swine. The genome of the virus codes for five major proteins, glycoprotein $(\mathrm{G})$, matrix protein $(\mathrm{M})$, nucleoprotein $(\mathrm{N})$, large protein $(\mathrm{L})$, and phosphoprotein $(\mathrm{P})$. The $\mathrm{G}$ protein mediates both viral binding and host cell fusion with the endosomal membrane following endocytosis. The L and $\mathrm{P}$ proteins are subunits of the viral RNA-dependent RNA polymerase.

The simple structure and rapid high-titer growth of VSV in mammalian and many other cells has made it a useful tool in the fields of cellular and molecular biology and virology, and this was further strengthened with the establishment of the reverse 
genetics system for VSV. Recombinant VSV in which native envelope $G$ protein is replaced with a foreign reporter gene such as a fluorescent reporter protein, luciferase, or secreted alkaline phosphatase (SEAP) can normally bud from producing cells even in the absence of $G$ protein, and heterologous viral envelope proteins are incorporated into the virion. Previous studies demonstrated that VSV forms a "pseudotype" when a cell is co-infected with VSV and other enveloped viruses (Huang et al., 1974; Witte and Baltimore, 1977). A pseudotype virus is defined as a viral particle harboring other types of viral envelopes or host cellular proteins with or without its own envelope. By virtue of these characteristics of VSV, pseudotype virus systems, in which VSV $G$ proteins are completely replaced with other types of viral envelope proteins, have been established (Figure 1). Up to the present, numerous types of pseudotype viruses have been constructed with heterologous viral envelope proteins and used in studies examining the entry of viruses, for identification of novel viral receptors, for development of neutralization tests, and as vaccine vectors (Table 1). In particular, availability of pseudotype viruses has been useful in the study of several high-risk viruses that require high-level containment facilities, i.e., in the handling of BSL-3 or -4 viruses. Infectivity of these pseudotype viruses can be easily and quantitatively evaluated by measurement of the reporter gene activities. A recombinant virus system, which encodes a heterologous viral envelope gene instead of an envelope gene in its own genome, has also been made available by establishment of reverse genetics (Figure 2). This recombinant virus is replication-competent both in vitro and in vivo and can contribute to the study of targeted viruses that inefficiently replicate in experimental systems. Although the pseudotype virus is limited to single-step infection and therefore provides a poor model for actual infection processes, the recombinant virus is a far more authentic and powerful tool for investigating targeted viral infection. Currently, this system is applicable to the VSV or other

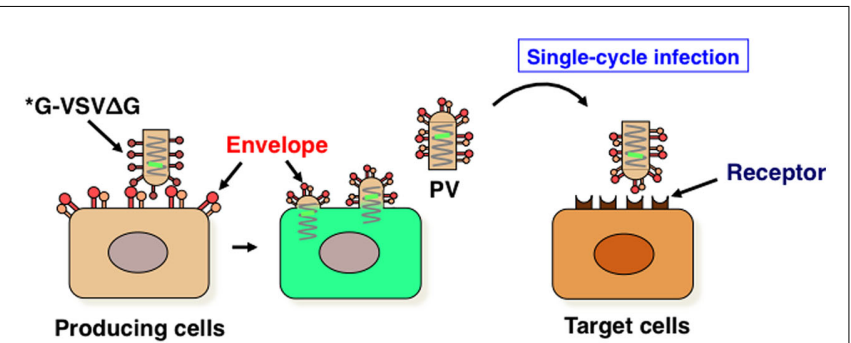

Characteristics of pseudotype virus (PV)

$>$ Viral entry can be examined because of single-cycle infection.

$>$ Can be operated with safety.

- Constructed easily, but only in cells that exhibit high competency of transfection.

FIGURE 1 | Schematic representation of the production of pseudotype VSV. Producer cells were transfected with an expression plasmid encoding foreign envelope genes and then infected with a VSV G-complemented pseudotype virus ( ${ }^{*} \mathrm{G}-\mathrm{VSV} \Delta \mathrm{G}$ ). The pseudotype virus released from the producer cells infected target cells but was not able to produce infectious progeny viruses. several viruses and not to retroviruses or lentiviruses. Recombinant VSV can be produced in various cells without regard to transfection efficiency; on the other hand, recovery of pseudotype VSV as well as pseudotype retroviruses or lentiviruses is restricted to $293 \mathrm{~T}$ or some other type of cells that exhibit a high competency of transfection. Recombinant VSV could also lead to the induction of cellular and humoral host immunity (Schnell et al., 1996).

\section{CONSTRUCTION OF PSEUDOTYPE AND RECOMBINANT VSV}

Seeded or recombinant VSVs in which the G gene is replaced by a foreign reporter gene such as a fluorescent reporter protein (green fluorescent protein, GFP; red fluorescent protein, RFP; and so on), luciferase, or SEAP or each viral envelope gene were generated as described below. Either 293T or BHK cells were grown to $90 \%$ confluence on $35-\mathrm{mm}$ tissue culture plates. The cells were infected with a recombinant vaccinia virus encoding the bacteriophage T7 RNA polymerase (vTF7-3) at a multiplicity of infection (MOI) of 5 . After incubation at room temperature for $1 \mathrm{~h}$, the cells were transfected with helper plasmids, $\mathrm{pBS}-\mathrm{N}$, pBS-P, pBS-L, and pBS-G, and template plasmids, pVSV $\Delta \mathrm{G}-$ GFP (RFP), pVSV $\Delta$ G-Luci, pVSV $\Delta$ G-SEAP, or pVSV $\Delta$ G-Env using a cationic liposome reagent. After $4 \mathrm{~h}$, the supernatants were

Table 1 | Application studies of pseudotype and recombinant VSV.

\begin{tabular}{|c|c|}
\hline Target viruses & Reference \\
\hline \multicolumn{2}{|c|}{ CHARACTERIZATION OF GLYCOPROTEIN, ENTRY TROPISM, ETC. } \\
\hline Ebola virus & Takada et al. (1997) \\
\hline \multirow[t]{3}{*}{$\mathrm{HCV}$} & Lagging et al. (1998) \\
\hline & Matsuura et al. (2001) \\
\hline & Tani et al. (2007) \\
\hline HIV-1 & Boritz et al. (1999) \\
\hline Measles virus & Tatsuo et al. (2000) \\
\hline HTLV-1 & Okuma et al. (2001) \\
\hline RSV & Kahn et al. (2001) \\
\hline SARS-CoV & Fukushi et al. (2005) \\
\hline HBV & Saha et al. (2005) \\
\hline Arenavirus & Vela et al. (2007) \\
\hline JEV & Tani et al. (2010) \\
\hline Baculovirus & Kaname et al. (2010) \\
\hline LCMV & Muik et al. (2011) \\
\hline \multicolumn{2}{|l|}{ VACCINE VECTORS } \\
\hline Influenza Virus & Roberts et al. (1998) \\
\hline Papillomavirus & Roberts et al. (2004) \\
\hline Marburg, Ebola, Lassa & Garbutt et al. (2004) \\
\hline HIV-1 & Publicover et al. (2005) \\
\hline West Nile virus & lyer et al. (2009) \\
\hline HBV & Cobleigh et al. (2010) \\
\hline Norovirus & Ma and Li (2011) \\
\hline \multicolumn{2}{|l|}{ DIAGNOSIS } \\
\hline Borna disease virus & Perez et al. (2001) \\
\hline Hantaan Virus & Lee et al. (2006) \\
\hline SARS-CoV & Fukushi et al. (2006) \\
\hline Nipah virus & Kaku et al. (2009) \\
\hline
\end{tabular}




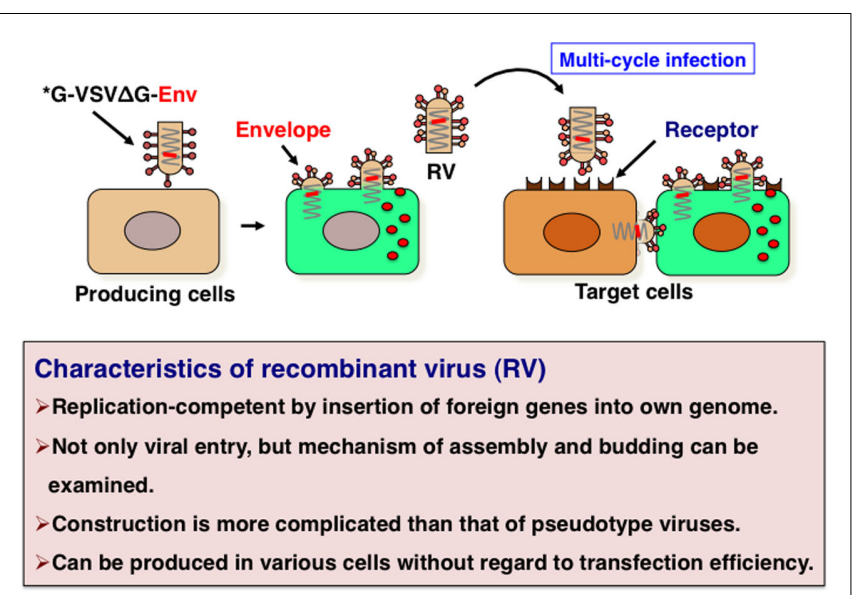

FIGURE 2 | Schematic representation of the production of recombinant VSV. Various mammalian producer cells were inoculated with a VSV G-complemented recombinant virus encoding foreign envelope genes instead of VSV G. The recombinant VSV was able to undergo a fully productive infection generating infectious progeny viruses that could be passaged into naïve cells.

replaced with $10 \%$ FBS DMEM, and cells were incubated at $37^{\circ} \mathrm{C}$ for $48 \mathrm{~h}$. The supernatants were then filtered through a $0.22-\mu \mathrm{m}$ pore-size filter to remove vaccinia virus and were applied to $293 \mathrm{~T}$ or BHK cells that had been transfected with pCAGVSVG $24 \mathrm{~h}$ previously. If $\mathrm{BHK}$ cells constitutively expressing the bacteriophage T7 RNA polymerase (BHKT7) were utilized, the cells were only transfected with helper plasmids, pIRES-N, pIRES-P, pIRES-L, pIRES-G, and template plasmids using a cationic liposome reagent without the vaccinia virus infection. Recovery of the virus was assessed by examining the cells for the cytopathic effects that are typical of a VSV infection after $24 \mathrm{~h}$. Stock of * G-complemented viruses, i.e., VSV $\Delta \mathrm{G}$ virus or recombinant viruses transiently bearing VSV G protein on the virion surface, were grown from the single plaque on BHK cells transfected with pCAGVSVG and then stored at $-80^{\circ} \mathrm{C}$. The infectious titers of the recovered viruses were determined by a plaque assay. To generate pseudotype virus, 293T, BHK, or some other type of cells that exhibit a high competency of transfection were transfected with a plasmid expressing the envelope protein using a cationic liposome reagent. After $24 \mathrm{~h}$ of incubation at $37^{\circ} \mathrm{C}$, cells were infected at an MOI of 0.5 with the ${ }^{*} \mathrm{G}-\mathrm{VSV} \Delta \mathrm{G}-$ Luci and ${ }^{*} \mathrm{G}-\mathrm{VSV} \Delta \mathrm{G}-\mathrm{SEAP}$, or 5 with ${ }^{*} \mathrm{G}-\mathrm{VSV} \Delta \mathrm{G}-$ GFP (RFP). The virus was adsorbed for $2 \mathrm{~h}$ at $37^{\circ} \mathrm{C}$ and then extensively washed four times or more with serum-free DMEM. After $24 \mathrm{~h}$ of incubation at $37^{\circ} \mathrm{C}$, the culture supernatants were collected, centrifuged to remove cell debris, and stored at $-80^{\circ} \mathrm{C}$. To generate recombinant virus in various mammalian cells, cells were infected with the ${ }^{*} \mathrm{G}$-complemented VSV $\Delta \mathrm{G}$-Env at an MOI of 5 for $2 \mathrm{~h}$ at $37^{\circ} \mathrm{C}$ and then extensively washed four times or more with serum-free DMEM. After $24 \mathrm{~h}$ of incubation at $37^{\circ} \mathrm{C}$, the culture supernatants were collected and stored at $-80^{\circ} \mathrm{C}$. The infectious titers of the viruses were determined by evaluation of each reporter assay or a focus-forming assay. Further details of the protocol can be found in a recent paper (Whitt, 2010).

\section{APPLICATION IN THE STUDY OF ENTRY MECHANISMS OF HCV}

Hepatitis $\mathrm{C}$ virus has already infected more than $3 \%$ of the worldwide population and $80 \%$ of those infected develop persistent HCV infection (Cerny and Chisari, 1999; Theodore and Fried, 2000). Persistent HCV infection often leads to chronic hepatitis, hepatic steatosis, cirrhosis, and hepatocellular carcinoma. Currently, there are still 1.5 million or more HCV carriers in Japan. In past years, anti-hepatitis $\mathrm{C}$ therapy has modestly improved; however, a currently available combination therapy, consisting of interferon and the nucleoside analog, ribavirin, shows a sustained response in only less than half of the treated patients. The development of innovative treatment alternatives for patients infected with HCV is urgently required, and a better understanding of the life cycle of HCV should allow us to improve HCV therapies. However, due to the lack of an in vitro cell culture system for the isolation of virus directly from patient sera at present, various surrogate systems such as replicon cells (Lohmann et al., 1999), pseudotype viruses (Lagging et al., 1998; Matsuura et al., 2001; Bartosch et al., 2003; Hsu et al., 2003; Tani et al., 2007), or trans-complement particles (Ishii et al., 2008; Steinmann et al., 2008) have been developed to study each step of HCV infection. Although in vitro binding assays using soluble purified envelope proteins or HCV-LPs have identified several candidate receptors for $\mathrm{HCV}$, the final determination of a true entry receptor or coreceptor capable of internalizing $\mathrm{HCV}$ may be made using an infection assay. Toward this end, pseudotype virus systems based on VSV and retrovirus or lentivirus have been established and applied to identify entry receptors for HCV. Although it is still unknown how HCV envelope proteins retained in the endoplasmic reticulum (ER) are incorporated into both VSV and retroviruses, which naturally bud from the plasma membrane, significant infectivity of these pseudotype viruses has been exhibited in several human hepatoma cell lines. These infections could be inhibited by treatment with antibodies or soluble proteins against putative receptors or HCV envelope proteins, or by a knockdown of receptor molecules by small interfering RNAs (siRNAs), suggesting that innate HCV infection had occurred. We also successfully generated infectious pseudotype and recombinant VSVs incorporating unmodified HCV envelope proteins in hepatic and non-hepatic human cell lines. These viruses exhibited high infectivity in a human hepatoma cell line, Huh7, which is highly susceptible to infection by cell-cultured $\mathrm{HCV}$ (HCVcc). The recombinant virus, but not the pseudotype virus, was able to propagate and form foci only in Huh7 cells. The infection of Huh7 cells with pseudotype and recombinant viruses was inhibited by anti-hCD81 and anti-E2 antibodies and by sera from chronic HCV patients. These viruses, as well as pseudotype retroviruses (HCVpp) or HCVcc, were sensitive to the inhibitors of vacuolar acidification, such as ammonium chloride, concanamycin $\mathrm{A}$, or bafilomycin $\mathrm{A}_{1}$, or formation of clathrin-coated pits, chlorpromazine, suggesting that these viruses enter via $\mathrm{pH}$-dependent and clathrin-mediated endocytosis into target cells (Blanchard et al., 2006; Tani et al., 2007). The infectivity of the recombinant virus was inhibited by an ER $\alpha$ glucosidase inhibitor, $N$-( $n$-nonyl) deoxynojirimycin $(N n$-DNJ), but not by a Golgi mannosidase inhibitor, deoxymannojirimycin 
(Tani et al., 2007). Focus formation of the recombinant virus was also impaired by $\mathrm{Nn}$-DNJ treatment. It was obvious that the appearance of infectious or non-infectious viruses was dependent on the cell type as a result of the infectivity of the recombinant viruses generated from various cell lines. Although the precise mechanisms of HCV assembly or budding that cause the differences in infectivity of viruses generated from different cell lines is still unclear, host cellular factors might be involved in the assembly or budding steps in the generation of infectious particles.

\section{APPLICATION IN THE STUDY OF ENTRY MECHANISMS OF JEV}

Japanese encephalitis virus, a mosquito-borne zoonotic pathogen, is the leading cause of viral encephalitis in humans, with $\sim 50,000$ cases reported annually worldwide. JEV is an enveloped virus belonging to the family Flaviviridae and the genus Flavivirus, which also includes Dengue virus, West Nile virus, Yellow fever virus, and Tick-borne encephalitis virus (Gubler et al., 2007). The genome consists of a single-stranded positive-sense RNA of approximately $11 \mathrm{~kb}$, encoding a single large polyprotein, which is cleaved by host- and virus-encoded proteases into three structural (C, PrM, and E) and non-structural (NS1, NS2A, NS2B, NS3, NS4A, NS4B, and NS5) proteins. The envelope protein (E) is a $53-\mathrm{kDa}$ glycoprotein, which is a major component of the virion surface and has been found to be associated with all the biological properties of the virus, such as attachment to cellular receptors, penetration, fusion with the endosomal membrane, host cell range and cell tropism, and neutralization to antibodies. Although a number of cellular components that interacted with E protein, such as heat shock cognate protein 70 (Ren et al., 2007), heat shock protein 70 (Das et al., 2009), vimentin (Das et al., 2011), glycosaminoglycans (Su et al., 2001; Lee and Lobigs, 2002), and laminin (Boonsanay and Smith, 2007), have been shown to participate in JEV binding or penetration, the precise mechanisms remain largely unknown. The pseudotype and recombinant VSV systems have offered us useful tools to focus on the study of entry mechanisms of JEV E proteins by using control viruses harboring an appropriate protein on identical particles. Both pseudotype (JEVpv) and recombinant (JEVrv) VSV bearing the JEV E protein exhibited high infectivity for the target cells, and JEVrv, but not JEVpv, was able to propagate and form foci, as did authentic JEV (Tani et al., 2010). Both JEVpv and JEVrv were neutralized by anti-JEV E antibodies. Treatment of cells with inhibitors for vacuolar ATPase and clathrin-mediated endocytosis reduced the infectivity of JEVpv, suggesting that JEVpv enters cells via $\mathrm{pH}$ - and clathrin-dependent endocytic pathways. Treatment of the JEVpv and JEVrv with cholesterol drastically reduced the infectivity, as previously reported on authentic JEV (Lee et al., 2008). In contrast, depletion of cholesterol from the viruses by treatment with methyl $\beta$-cyclodextrin enhanced the infectivity. Furthermore, treatment of cells with sphingomyelinase (SMase), which hydrolyzes membrane-bound sphingomyelin to ceramide, drastically enhanced infection with JEVpv and JEVrv (Tani et al., 2010). These enhancements were inhibited by treatment with an SMase inhibitor or $\mathrm{C}_{6}$-ceramide. Involvement of ceramide in the entry of JEV was confirmed by co-precipitation of the JEV E protein with labeled-ceramide (Tani et al., 2010). In our study, it was demonstrated that cellular lipid components such as cholesterol and ceramide play crucial roles in the entry of JEV. Modification of sphingolipids on the plasma membrane of the cells might be a novel target for the development of antivirals against JEV infection.

\section{APPLICATION IN THE STUDY OF COMPLEMENT RESISTANCE OF BACULOVIRUS GP64}

Baculovirus vectors have been shown to exhibit not only a highlevel of gene expression in insect cells but also efficient gene transduction into a wide variety of mammalian cells with lower cytotoxicity (Hofmann et al., 1995; Boyce and Bucher, 1996; Shoji et al., 1997). In contrast, the complement systems of animals have been defined to represent a potent primary barrier to in vivo application of baculovirus vectors produced in insect cells (Hofmann and Strauss, 1998; Tani et al., 2001, 2003). However, pseudotype viruses based on retroviruses or lentiviruses bearing baculovirus envelope protein GP64 have recently been shown to exhibit efficient gene transduction into mouse organs for long periods compared with those bearing the VSV G protein, which is commonly used for pseudotyping (Kumar et al., 2003; Schauber et al., 2004; Kang et al., 2005; Sinn et al., 2005, 2008). It was considered that serum resistance of the pseudotype viruses bearing GP64 protein is caused by differences between insect and mammalian cells, because pseudotype retroviruses or lentiviruses were generated from mammalian cells, and in contrast, baculovirus was generated from insect cells. Therefore, we generated recombinant VSV bearing GP64 protein in both insect and mammalian cells and examined the role of the GP64 on resistance to inactivation by human or guinea-pig sera (Kaname et al., 2010). Recombinant VSVs generated in human cell lines exhibited the incorporation of human decay accelerating factor (DAF) in virions and were resistant to serum inactivation, whereas those generated in insect cell lines exhibited no incorporation of human DAF and were sensitive to complement inactivation. Recombinant baculoviruses generated in insect cells expressing human DAF or carrying the human DAF gene exhibited resistance to complement inactivation, suggesting that acquisition of resistance to human complement by the incorporation of DAF with baculovirus GP64 represents a step in the development of novel viral vectors for improved gene therapy.

\section{APPLICATION IN THE STUDY OF VIRAL ENTRY AND NEUTRALIZATION TEST OF ARENAVIRUSES}

Viral hemorrhagic fever viruses, such as members of the Arenaviridae family, including Lassa virus, Junin virus, Machupo virus, and Chapare virus, cause fulminating disease characterized by acute fever followed by generalized hemorrhagic syndrome that is associated with $90 \%$ mortality in the severe forms.

Because these viruses cannot be handled under BSL-2 or 3 containment facilities, pseudotype viruses bearing each GPC envelope protein of various arenaviruses, such as Lassa virus, Junin virus, Machupo virus, Sabia virus, Chapare virus, Guanarito virus, and Lujo virus, were generated as surrogate models for the study of viral infection or neutralization. All of the pseudotype viruses exhibited high susceptibility to various cell lines and were neutralized by sera from patients infected with each virus. Reduction of the infectivity of the pseudotype virus 
in the cells treated with various entry inhibitors depended on the species of pseudotype virus, suggesting that several entry mechanisms were involved in the infection of arenaviruses (Tani et al., unpublished data). In studies on serological diagnosis of arenaviruses, cross reaction occurred among species of arenaviruses in enzyme-linked immunosorbent assay or immunofluorescence assay, whereas neutralization tests using pseudotype viruses exhibited a specific reaction with each species of virus (Nakauchi et al., 2009; Iha et al., unpublished data). Although Old or New World arenaviruses have been shown to utilize $\alpha$-dystroglycan or human transferrin receptor 1 , respectively, as one of the cellular receptors, infectivities of the pseudotype viruses have not been consistent with the expression levels of the receptor molecules in our preliminary studies. The infection of pseudotype viruses was not completely inhibited by soluble protein or antibodies of receptor molecules, suggesting that another receptor molecule(s) might be involved in the entry of these viruses. Although further characterization of the pseudotype viruses bearing GPC envelope proteins of arenaviruses will be needed, these viruses are thought to mimic the functional properties of wild type arenaviruses and are suitable for the study of entry mechanisms, including investigation of novel cellular receptor(s), neutralization tests, or vaccine development.

\section{CONCLUSION AND PERSPECTIVES}

Up to the present, various viral vectors aimed at gene transfer or therapy have been developed and applied in biological and

\section{REFERENCES}

Bartosch, B., Dubuisson, J., and Cosset, F. L. (2003). Infectious hepatitis $\mathrm{C}$ virus pseudo-particles containing functional E1-E2 envelope protein complexes. J. Exp. Med. 197, 633-642.

Blanchard, E., Belouzard, S., Goueslain, L., Wakita, T., Dubuisson, J., Wychowski, C., and Rouillé, Y. (2006). Hepatitis C virus entry depends on clathrin-mediated endocytosis. J. Virol. 80, 6964-6972.

Boonsanay, V., and Smith, D. R. (2007). Entry into and production of the Japanese encephalitis virus from $\mathrm{C} 6 / 36$ cells. Intervirology 50, 85-92.

Boritz, E., Gerlach, J., Johnson, J. E., and Rose, J. K. (1999). Replicationcompetent rhabdoviruses with human immunodeficiency virus type 1 coats and green fluorescent protein: entry by a $\mathrm{pH}$-independent pathway. J. Virol. 73, 6937-6945.

Boyce, F. M., and Bucher, N. L. (1996). Baculovirus-mediated gene transfer into mammalian cells. Proc. Natl. Acad. Sci. U.S.A. 93, 2348-2352.

Cerny, A., and Chisari, F. V. (1999). Pathogenesis of chronic hepatitis C: immunological features of hepatic

medical research fields. Pseudotype or recombinant VSV are useful tools as alternative viruses to study entry mechanisms, identification of novel cellular receptors, screening antiviral libraries, or development of serological diagnosis for various kinds of viruses, especially unmanageable BSL-3 or -4 viruses. These viruses have also been applied in targeting vectors to specific cells. VSV vectors with monoclonal antibodies against specific oncogenic proteins or viral receptor molecule(s) incorporated on virion surface have been targeted specifically to cells expressing oncogenic proteins or infected cells expressing the viral envelope proteins, respectively, without any influences on normal or uninfected cells. This raises the possibility of the elimination of cancer cells or chronic viral infections by using acute VSV infection. Genetically engineered VSVs encoding suicide cassettes or immune response genes have also been generated as more specific, safer, and effective agents for cancer therapies. Further studies and applications of VSV vectors will provide us not only with useful tools for virological studies but also various benefits for biological sciences and medical research.

\section{ACKNOWLEDGMENTS}

This work was supported in part by grants-in-aid from the Ministry of Health, Labour and Welfare; the Ministry of Education, Culture, Sports, Science, and Technology; the 21st Century Center of Excellence Program of Japan; the Global Center of Excellence Program; and the Foundation for Biomedical Research and Innovation, Japan.

Morikawa, S. (2005). Vesicular stomatitis virus pseudotyped with severe acute respiratory syndrome coronavirus spike protein. J. Gen. Virol.86, 2269-2274.

Garbutt, M., Liebscher, R., Wahl-Jensen, V., Jones, S., Möller, P., Wagner, R., Volchkov, V., Klenk, H. D., Feldmann, H., and Ströher, U. (2004). Properties of replicationcompetent vesicular stomatitis virus vectors expressing glycoproteins of filoviruses and arenaviruses. J. Virol. 78, 5458-5465.

Gubler, D., Kuno, G., and Markoff, L. (2007). "Flaviviruses, 1153-1252," in Fields Virology, 5th Edn, Vol. 1, eds D. M. Knipe and P. M. Howley (Philadelphia, PA: LippincottWilliams \& Wilkins), 1153-1252.

Hofmann, C., Sandig, V., Jennings, G., Rudolph, M., Schlag, P., and Strauss, M. (1995). Efficient gene transfer into human hepatocytes by baculovirus vectors. Proc. Natl. Acad. Sci. U.S.A. 92, 10099-10103.

Hofmann, C., and Strauss, M. (1998). Baculovirus-mediated gene transfer in the presence of human serum or blood facilities by inhibition of the complement system. Gene Ther. 5, 531-536.
Hsu, M., Zhang, J., Flint, M., Logvinoff, C., Cheng-Mayer, C., Rice, C. M., and McKeating, J. A. (2003). Hepatitis $\mathrm{C}$ virus glycoproteins mediate $\mathrm{pH}$ dependent cell entry of pseudotyped retroviral particles. Proc. Natl. Acad. Sci. U.S.A. 100, 7271-7276.

Huang, A. S., Palma, E. L., Hewlett, N., and Roizman, R. (1974). Pseudotype formation between enveloped RNA and DNA viruses. Nature 252, 743-745.

Ishii, K., Murakami, K., Hmwe, S. S., Zhang, B., Li, J., Shirakura, M., Morikawa, K., Suzuki, R., Miyamura, T., Wakita, T., and Suzuki, T. (2008). Trans-encapsidation of hepatitis C virus subgenomic replicon RNA with viral structure proteins. Biochem. Biophys. Res. Commun. 371, 446-450.

Iyer, A. V., Pahar, B., Boudreaux, M. J., Wakamatsu, N., Roy, A. F., Chouljenko, V. N., Baghian, A., Apetrei, C., Marx, P. A., and Kousoulas, K. G. (2009). Recombinant vesicular stomatitis virus-based West Nile vaccine elicits strong humoral and cellular immune responses and protects mice against lethal challenge with the virulent West Nile virus strain LSU-AR01. Vaccine 27, 893-903. 
Kahn, J. S., Roberts, A., Weibel, C., Buonocore, L., and Rose, J. K. (2001). Replication-competent or attenuated, nonpropagating vesicular stomatitis viruses expressing respiratory syncytial virus (RSV) antigens protect mice against RSV challenge. J. Virol. 75, 11079-11087.

Kaku, Y., Noguchi, A., Marsh, G. A., McEachern, J. A., Okutani, A., Hotta, K., Bazartseren, B., Fukushi, S., Broder, C. C., Yamada, A., Inoue, S., and Wang, L. F. (2009). A neutralization test for specific detection of Nipah virus antibodies using pseudotyped vesicular stomatitis virus expressing green fluorescent protein. J. Virol. Methods. 160, 7-13.

Kaname, Y., Tani, H., Kataoka, C., Shiokawa, M., Taguwa, S., Abe, T., Moriishi, K., Kinoshita, T., and Matsuura, Y. (2010). Acquisition of complement resistance through incorporation of CD55/decay-accelerating factor into viral particles bearing baculovirus GP64. J. Virol. 84, 3210-3219.

Kang, Y., Xie, L., Tran, D. T., Stein, C. S., Hickey, M., Davidson, B. L., and McCray, P. B. Jr. (2005). Persistent expression of factor VIII in vivo following nonprimate lentiviral gene transfer. Blood 106, 1552-1558.

Kumar, M., Bradow, B. P., and Zimmerberg, J. (2003). Large-scale production of pseudotyped lentiviral vectors using baculovirus GP64. Hum. Gene Ther. 14, 67-77.

Lagging, L. M., Meyer, K., Owens, R. J., and Ray, R. (1998). Functional role of hepatitis $\mathrm{C}$ virus chimeric glycoproteins in the infectivity of pseudotyped virus. J. Virol. 72, 3539-3546.

Lee, C. J., Lin, H. R., Liao, C. L., and Lin, Y. L. (2008). Cholesterol effectively blocks entry of flavivirus. J. Virol. 82, 6470-6480.

Lee, E., and Lobigs, M. (2002). Mechanism of virulence attenuation of glycosaminoglycan-binding variants of Japanese encephalitis virus and Murray Valley encephalitis virus. J. Virol. 76, 4901-4911.

Lee, B. H., Yoshimatsu, K., Araki, K., Okumura, M., Nakamura, I., and Arikawa, J. (2006). A pseudotype vesicular stomatitis virus containing Hantaan virus envelope glycoproteins G1 and G2 as an alternative to hantavirus vaccine in mice. Vaccine 24, 2928-2934.

Lohmann, V., Körner, F., Koch, J., Herian, U., Theilmann, L., and Bartenschlager, R. (1999). Replication of subgenomic hepatitis $\mathrm{C}$ virus RNAs in a hepatoma cell line. Science 285 , 110-113.
Ma, Y., and Li, J. (2011). Vesicular stomatitis virus as a vector to deliver virus-like particles of human norovirus: a new vaccine candidate against an important noncultivable virus. J. Virol. 85, 2942-2952.

Matsuura, Y., Tani, H., Suzuki, K. Kimura-Someya, T., Suzuki, R., Aizaki, H., Ishii, K., Moriishi, K., Robison, C. S., Whitt, M. A., and Miyamura, T. (2001). Characterization of pseudotype VSV possessing HCV envelope proteins. Virology 286, 263-275.

Muik, A., Kneiske, I., Werbizki, M., Wilflingseder, D., Giroglou, T., Ebert, O., Kraft, A., Dietrich, U., Zimmer, G., Momma, S., and von Laer, D. (2011). Pseudotyping vesicular stomatitis virus with lymphocytic choriomeningitis virus glycoproteins enhances infectivity for glioma cells and minimizes neurotropism. J. Virol. 85, 5679-5684.

Nakauchi, M., Fukushi, S., Saijo, M., Mizutani, T., Ure, A. E., Romanowski, V., Kurane, I., and Morikawa, S. (2009). Characterization of monoclonal antibodies to Junin virus nucleocapsid protein and application to the diagnosis of hemorrhagic fever caused by South American arenaviruses. Clin. Vaccine Immunol. 16, 1132-1138.

Okuma, K., Matsuura, Y., Tatsuo, H., Inagaki, Y., Nakamura, M., Yamamoto, N., and Yanagi, Y. (2001). Analysis of the molecules involved in human T-cell leukemia virus type 1 entry by a vesicular stomatitis virus pseudotype bearing its envelope glycoproteins. J. Gen. Virol. 82, 821-830.

Perez, M., Watanabe, M., Whitt, M. A., and de la Torre, J. C. (2001). Nterminal domain of Borna disease virus $\mathrm{G}$ (p56) protein is sufficient for virus receptor recognition and cell entry. J. Virol. 75, 7078-7085.

Publicover, J., Ramsburg, E., and Rose, J. K. (2005). A single-cycle vaccine vector based on vesicular stomatitis virus can induce immune responses comparable to those generated by a replication-competent vector. $J$. Virol. 79, 13231-13238.

Ren, J., Ding, T., Zhang, W., Song, J., and Ma, W. (2007). Does Japanese encephalitis virus share the same cellular receptor with other mosquitoborne flaviviruses on the C6/36 mosquito cells? Virol. J. 4, 83.

Roberts, A., Kretzschmar, E., Perkins, A. S., Forman, J., Price, R., Buonocore, L., Kawaoka, Y., and Rose, J. K. (1998). Vaccination with a recombinant vesicular stomatitis virus expressing an influenza virus hemagglutinin provides complete protection from influenza virus challenge. J. Virol. 72, 4704-4711.

Roberts, A., Reuter, J. D., Wilson, J. H., Baldwin, S., and Rose, J. K. (2004) Complete protection from papillomavirus challenge after a single vaccination with a vesicular stomatitis virus vector expressing high levels of L1 protein. J. Virol. 78, 3196-3199.

Saha, M. N., Tanaka, A., Jinno-Oue, A., Shimizu, N., Tamura, K., Shinagawa, M., Chiba, J., and Hoshino, H. (2005). Formation of vesicular stomatitis virus pseudotypes bearing surface proteins of hepatitis B virus. J. Virol. 79, 12566-12574.

Schauber, C. A., Tuerk, M. J., Pacheco, C. D., Escarpe, P. A., and Veres, G. (2004). Lentiviral vectors pseudotyped with baculovirus gp64 efficiently transduce mouse cells in vivo and show tropism restriction against hematopoietic cell types in vitro. Gene Ther. 11, 266-275.

Schnell, M. J., Buonocore, L., Kretzschmar, E., Johnson, E., and Rose, J. K. (1996). Foreign glycoproteins expressed from recombinant vesicular stomatitis viruses are incorporated efficiently into virus particles. Proc. Natl. Acad. Sci. U.S.A. 93 11359-11365.

Shoji, I., Aizaki, H., Tani, H., Ishii, K., Chiba, T., Saito, I., Miyamura, T., and Matsuura, Y. (1997). Efficient gene transfer into various mammalian cells, including non-hepatic cells, by baculovirus vectors. J. Gen Virol. 78, 2657-2664.

Sinn, P. L., Arias, A. C., Brogden, K. A., and McCray, P. B. Jr. (2008). Lentivirus vector can be readministered to nasal epithelia without blocking immune responses. J. Virol. 82, 10684-10692.

Sinn, P. L., Burnight, E. R., Hickey, M. A., Blissard, G. W., and McCray, P. B. Jr. (2005). Persistent gene expression in mouse nasal epithelia following feline immunodeficiency virusbased vector gene transfer. J. Virol. 79, 12818-12827.

Steinmann, E., Brohm, C., Kallis, S., Bartenschlager, R., and Pietschmann, T. (2008). Efficient trans-encapsidation of hepatitis $\mathrm{C}$ virus RNAs into infectious virus-like particles. J. Virol. 82, 7034-7046.

Su, C. M., Liao, C. L., Lee, Y. L. and Lin, Y. L. (2001). Highly sulfated forms of heparin sulfate are involved in Japanese encephalitis virus infection. Virology 286, 206-215.
Takada, A., Robison, C., Goto, H., Sanchez, A., Murti, K. G., Whitt, M. A., and Kawaoka, Y. (1997). A system for functional analysis of Ebola virus glycoprotein. Proc. Natl. Acad. Sci. USA. 94, 14764-14769.

Tani, H., Komoda, Y., Matsuo, E., Suzuki, K., Hamamoto, I., Yamashita, T., Moriishi, K., Fujiyama, K., Kanto, T., Hayashi, N., Owsianka, A., Patel, A. H., Whitt, M. A., and Matsuura, Y. (2007). Replicationcompetent recombinant vesicular stomatitis virus encoding hepatitis $\mathrm{C}$ virus envelope proteins. J. Virol. 81, 8601-8612.

Tani, H., Limn, C. K., Yap, C. C., Onishi, M., Nozaki, M., Nishimune, Y., Okahashi, N., Kitagawa, Y., Watanabe, R., Mochizuki, R., Moriishi, K., and Matsuura, Y. (2003). In vitro and in vivo gene delivery by recombinant baculoviruses. J. Virol. 77, 9799-9808.

Tani, H., Nishijima, M., Ushijima, H., Miyamura, T., and Matsuura, Y. (2001). Characterization of cellsurface determinants important for baculovirus infection. Virology 279 343-353.

Tani, H., Shiokawa, M., Kaname, Y., Kambara, H., Mori, Y., Abe, T., Moriishi, K., and Matsuura, Y. (2010). Involvement of ceramide in the propagation of Japanese encephalitis virus. J. Virol. 84 2798-2807.

Tatsuo, H., Okuma, K., Tanaka, K., Ono, N., Minagawa, H., Takade, A., Matsuura, Y., and Yanagi, Y. (2000). Virus entry is a major determinant of cell tropism of Edmonston and wild-type strains of measles virus as revealed by vesicular stomatitis virus pseudotypes bearing their envelope proteins. J. Virol. 74, 4139-4145.

Theodore, D., and Fried, M. W. (2000). Natural history and disease manifestations of hepatitis $\mathrm{C}$ infection. Curr. Top. Microbiol. Immunol. 242, 43-54.

Vela, E. M., Zhang, L., Colpitts, T. M., Davey, R. A., and Aronson, J. F. (2007). Arenavirus entry occurs through a cholesterol-dependent, non-caveolar, clathrin-mediated endocytic mechanism. Virology 369, $1-11$.

Whitt, M. A. (2010). Generation of VSV pseudotypes using recombinant $\triangle \mathrm{G}$-VSV for studies on virus entry, identification of entry inhibitors, and immune responses to vaccines. J. Virol. Methods 169, 365-374.

Witte, O. N., and Baltimore, D. (1977). Mechanism of formation of pseudotypes between 
vesicular stomatitis virus and murine leukemia virus. Cell 11, 505-511.

Conflict of Interest Statement: The authors declare that the research was conducted in the absence of any commercial or financial relationships that could be construed as a potential conflict of interest.

Received: 09 December 2011; paper pending published: 18 December 2011; accepted: 21 December 2011; published online: 18 January 2012.
Citation: Tani H, Morikawa S and Matsuura $Y$ (2012) Development and applications of VSV vectors based on cell tropism. Front. Microbio. 2:272. doi 10.3389/fmicb.2011.00272

This article was submitted to Frontiers in Virology, a specialty of Frontiers in Microbiology.
Copyright (C) 2012 Tani, Morikawa and Matsuura. This is an open-access article distributed under the terms of the Creative Commons Attribution Non Commercial License, which permits noncommercial use, distribution, and reproduction in other forums, provided the original authors and source are credited. 